\title{
Unforeseen movement of crude oil spill through beach sand
}

\section{Opinion}

Oil spill material released by the 2010 Deepwater Horizon accident contaminated a majority of the 100 kilometers of Alabama coastline. In response to the oil spill, BP sprayed a dispersant, Corexit 9500A, as an initial remediation effort. An unforeseen impact of the saltwaterdispersant mixture includes the mobilization of oil-spilled material into the underlying beach sand. This study investigated the effect of the dispersant to promote gravitational drainage by measuring the physical characteristics of the sand, saltwater, crude oil, and the dispersant solution. The saltwater-dispersant mixture promoted the downward movement of oil mass 20 times greater extent than just saltwater. These tests are meant to simulate spill material on the beach being exposed to a low-energy, 1-meter semidiurnal tide occurring along the Alabama coastline. A separate test simulated oil-wet sand exposed to saltwater and a saltwater-dispersant mixture. The oilwet sand impeded the vertical movement of saltwater, but allowed a saltwater-dispersant solution to mobilize the oil to migrate downward. The mobilization of oil in this three phase system of saltwater, oil, and air is controlled by: the pressure-saturation profile of the sand; interfacial tension with saltwater; and its surface tension with air. There are additional problems associated with the use of dispersants. As the dispersant spreads and approaches the coastline, the salinity of the marine system changes to a brackish one and eventually to a freshwater system. Does a change in salinity alter the dispersant capability? ${ }^{1}$ stated that a critically small oil droplet of about 10 micrometers $(\mathrm{mm})$ in diameter needs to be reached in dispersed oil so that the oil droplets do not coalesce thereby negating the dispersant activity. Interfacial tensions and the formation of critical micelle concentration in hydrocarbon mixtures are difficult to model as the molar fractions change. ${ }^{2}$ Arrival of oil material on the Alabama beach during high tide would be degraded and reformed into tarballs or a tarmat. The downward movement would be caused mostly by displacement of oil globules by draining seawater through beach sand. Seawater drainage is occurring during the change from a high tide to a low tide environment. Alabama beaches are classified as lowenergy. ${ }^{3}$ Therefore, vertical migration is probably due to oil globules coalescing, and displacing air in pores that formed during the change
Volume I Issue I - 2017

\author{
David Steffy \\ Department of Chemistry and Geosciences, Jacksonville State \\ University, USA
}

Correspondence: David Steffy, Department of Chemistry and Geosciences, Jacksonville State University, Jacksonville, Alabama, USA, Email dsteffy@jsu.edu

Received: June 30, 2017 | Published: July 14, 2017

from high to low tides. This vertical movement would be enhanced by the presence of a dispersant. Laboratory measurements of Corexit 9500A have indicated that surface tension of saltwater becomes lowered substantially with a concentration of $0.5 \%$ Corexit 9500A. The remediation effort of beach sand would appear to be more than a surface response. Investigation below the surface to several meters below the fluctuating water table would be needed.

\section{Acknowledgements}

None

\section{Conflicts of Interest}

The author declares no conflicts of interest.

\section{References}

1. Zhengkai Li, Kenneth Lee, Paul E Kepkey, et.al. Monitoring dispersed oil droplets size distribution at the Gulf of Mexico Deepwater Horizon spill site. International Oil Spill Conference Proceedings. 2011;2011(1):377.

2. Yoon H, Oostroom M, Werth CI. Estimation of Interfacial Tension between organic liquid mixtures and water. Environ Sci Technol. 2009;43(20):7754-7761.

3. Morton RA, Peterson RL. Alabama-Mississippi Coastal Classification Maps-Perdido Pass to Cat Island. USGS Open File Report 2005-1151. 